\title{
Review on carbon emissions, energy consumption and low-carbon economy in China from a perspective of global climate change
}

\author{
SHEN Lei ${ }^{1},{ }^{*}$ SUN Yanzhi ${ }^{1,2}$ \\ 1. Institute of Geographic Sciences and Natural Resources Research, CAS, Beijing 100101, China; \\ 2. University of Chinese Academy of Sciences, Beijing 100049, China
}

\begin{abstract}
Accompanying the rapid growth of China's population and economy, energy consumption and carbon emission increased significantly from 1978 to 2012. China is now the largest energy consumer and $\mathrm{CO}_{2}$ emitter of the world, leading to much interest in researches on the nexus between energy consumption, carbon emissions and low-carbon economy. This article presents the domestic Chinese studies on this hotpot issue, and we obtain the following findings. First, most research fields involve geography, ecology and resource economics, and research contents contained some analysis of current situation, factors decomposition, predictive analysis and the introduction of methods and models. Second, there exists an inverted "U-shaped" curve connection between carbon emission, energy consumption and economic development. Energy consumption in China will be in a low-speed growth after 2035 and it is expected to peak between 6.19-12.13 billion TCE in 2050. China's carbon emissions are expected to peak in 2035, or during 2020 to 2045, and the optimal range of carbon emissions is between 2.4-3.3 PgC/year ( $1 \mathrm{PgC}=1$ billion tons $\mathrm{C}$ ) in 2050 . Third, future research should be focused on global carbon trading, regional carbon flows, reforming the current energy structure, reducing energy consumption and innovating the low-carbon economic theory, as well as establishing a comprehensive theoretical system of energy consumption, carbon emissions and low-carbon economy.
\end{abstract}

Keywords: carbon emissions; energy consumption; low-carbon economy; global climate change

\section{Introduction}

The international community has placed much more emphases on the topic of global climate change over decades. In 2014, the Intergovernmental Panel on Climate Change (IPCC) released its fifth assessment report, which analyzed the causal relationship between human

Received: 2015-12-25 Accepted: 2016-04-06

Foundation: National Natural Science Foundation of China, No.41271547; Strategic Priority Research Program - Climate Change: Carbon Budget and Related Issues of the Chinese Academy of Sciences, No.XDA05010400; National Natural Science Foundation of China, No.41401644

Author: Shen Lei, Professor, E-mail: shenl@igsnrr.ac.cn

"Corresponding author: Sun Yanzhi, PhD Candidate, E-mail: sunyz.15b@igsnrr.ac.cn 
activity and global climate change, and emphasized the need to reduce greenhouse gas emissions and mitigate the effects of climate change (Qin, 2014).

Although the question regarding the global warming was first raised more than a century ago, researches about energy consumption and carbon emissions have made some progress recently (Figure 1). In the 19th century, researchers noted that carbon emissions from burning fossil fuels could contribute to global warming, discovering that $60 \%$ of greenhouse effect is induced by $\mathrm{CO}_{2}$ (Ozturk and Acaravci, 2010). Recent studies have estimated that the burning of fossil fuels contributes to $70 \%$ of total carbon emissions, and that human activity and energy consumptions are the primary causes of climate change (Zhang et al., 2012). On the one hand, economic growth depends on energy consumption, which results in carbon emission. On the other hand, reducing carbon emission will react on energy consumption, and restrict economic development (Zhang and Duan, 2012).

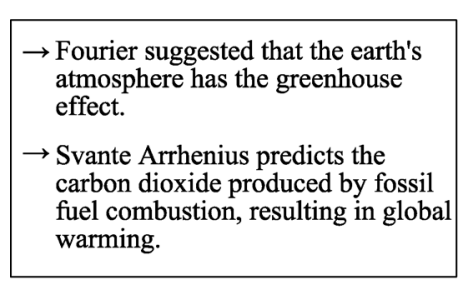

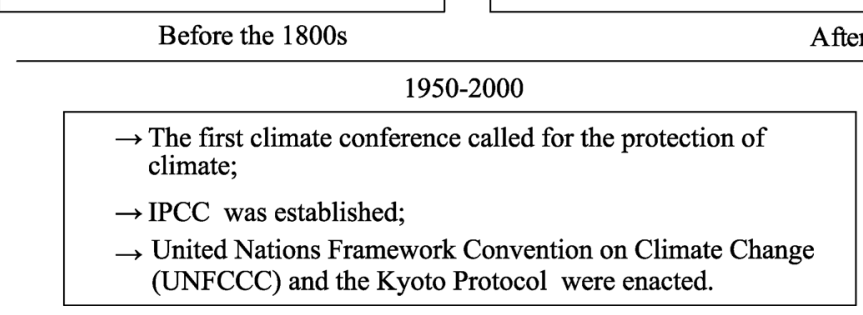

$\rightarrow$ United Nations Environment Programme (UNEP): As a result of global climate change, the glaciers are melting fast and many glaciers are likely to disappear in a decade;

$\rightarrow$ The IPCC Fifth Assessment Report: Over 95\% of climate change is induced by human possibility; if nomeasures are taken, the temperature may rise by $4.8^{\circ} \mathrm{C}$ in 2100 and by $2^{\circ} \mathrm{C}$ in 2050 .

Figure 1 The cognitive evolution of climate change

Research concerning the nexus between energy consumption, carbon emissions and economic development has been undertaken over many years. In 1991, Makarov explored the role of energy consumption in the Soviet economy (Makarov and Bashmakov, 1991); Nulíček denoted that national economic development could increase the energy intensity (Nulíček, 1993). Over the past years, academics from around the world have continued a variety of related studies, including fossil fuel emissions (Andres et al., 1996), industrial structure and carbon emissions (Tunç et al., 2009), energy efficiency and emissions (Greening et al., 2000), as well as on the linkage between energy consumption and economic development (Begum et al., 2015).

Due to the large population and rapidly growing economy, from 1978 to 2012, Chinese annual energy consumption increases from 571 million to 3.63 billion TCE, while carbon emissions increase from 400 million to 7.95 billion tons. During this period, China's energy consumption rises from $6 \%$ to $20.3 \%$ of the world's total, making it the world's largest consumer and emitter, with carbon emissions now accounting for $24.6 \%$, up from $8.4 \%$ (Fan et al., 2015). Energy consumption and carbon emissions cannot be controlled within a short time, but in the face of climate change, China must confront its urgent pressures to reduce the carbon emissions. This paper presents a summary of the related research, revealing the 
interaction mechanisms of the climate change, energy consumption and low-carbon development. It will help to support green development, cycle development and low carbon development of China's "13th Five-Year Plan" (2016-2020), and cope with the international climate change.

\section{Methodology}

In this article, we have collected 480 papers published in the database of China National Knowledge Infrastructure (CNKI) to summarize some progress of Chinese researchers in terms of three topic words of energy consumption, carbon emission and low-carbon economy. The topic words are processed at standardized level to control the use of the synonyms and polysemous words, promoting the precision and recall of the related literature. There are plenty of keywords under the topic words and we count all the keywords appearing in these papers. Keywords are the words occurring more frequently in the study and they can express the theme of literature. These papers are mainly published in some major journals, such as Acta Geographica Sinica, Journal of Natural Resources, and Economic Geography (Table 1).

Table 1 Related methods and information of this paper

\begin{tabular}{|c|c|c|c|c|}
\hline Methods & Topic word & High frequency keywords & $\begin{array}{l}\text { The number } \\
\text { of documents }\end{array}$ & Type of journal \\
\hline $\begin{array}{l}\text { Biliometric } \\
\text { analysis } \\
\text { Co-word Analysis }\end{array}$ & $\begin{array}{l}\text { 'energy consumption', } \\
\text { 'carbon emission', } \\
\text { 'low-carbon economy' }\end{array}$ & $\begin{array}{l}\text { LMDI model, } \\
\text { economy growth, } \\
\text { climate change, } \\
\text { carbon emission } \\
\text { reduction, decomposition } \\
\text { analysis, industrial } \\
\text { structure, } \\
\text { low-carbon, } \\
\text { carbon emission permits }\end{array}$ & 480 & $\begin{array}{l}\text { Acta Geographica } \\
\text { Sinica, Journal of } \\
\text { Natural Resources, } \\
\text { Economic Geography, } \\
\text { Resources Science, } \\
\text { China Population, } \\
\text { Resources and } \\
\text { Environment, } \\
\text { Ecological Economy } \\
\text { and others }\end{array}$ \\
\hline
\end{tabular}

Biliometric analysis and co-word analysis are applied to analyze these publications. In order to discuss the characteristics and variations of science, as a quantitative method based on mathematical statistics, the bibliometrics is used to examine the numerical relationship, changes regulation and quantitative management of the literature. Co-word analysis shows the frequency of any two keywords in one paper to reflect the close connection, and the higher frequency indicates the closer relation. Based on the biliometric analysis, we analyze the keywords in the 480 papers and then make the co-word matrix of the keywords, which appear more than 20 times (Table 2). Table 2 shows that carbon emission, low-carbon economy and energy consumption appear most frequently in these collected literatures, and the couple of carbon emission and energy consumption occurs more often than any other couple, with 59 times. Through the co-word analysis, the research focuses of subject are very obvious.

Basing on the collection of the research focuses, the rest sections of this article will present our literature analysis and main findings, indicating the status and trend of carbon emission, the nexus between energy consumption and carbon emissions, and some low-carbon economic models towards addressing the climate change, which will help to accelerate 
the green development goals in China during the 13th Five-Year Plan period. It will also provide some decision-making references to the development of renewable and low-carbon technologies necessary to combat global climate change.

Table 2 Co-word matrix of high frequency keywords (partial)

\begin{tabular}{|c|c|c|c|c|c|c|c|c|c|c|}
\hline & $\begin{array}{l}\text { Carbon } \\
\text { emis- } \\
\text { sion }\end{array}$ & $\begin{array}{c}\text { Low- } \\
\text { carbon } \\
\text { economy }\end{array}$ & $\begin{array}{c}\text { Energy } \\
\text { con- } \\
\text { sumption }\end{array}$ & $\begin{array}{l}\text { LMDI } \\
\text { model }\end{array}$ & $\begin{array}{l}\text { Eco- } \\
\text { nomic } \\
\text { growth }\end{array}$ & $\begin{array}{l}\text { Climate } \\
\text { change }\end{array}$ & $\begin{array}{l}\text { Carbon } \\
\text { reduction }\end{array}$ & $\begin{array}{l}\text { Decompo- } \\
\text { sition } \\
\text { analysis }\end{array}$ & $\begin{array}{l}\text { Industrial } \\
\text { structure }\end{array}$ & $\begin{array}{l}\text { Low- } \\
\text { carbon }\end{array}$ \\
\hline $\begin{array}{l}\text { Carbon } \\
\text { emission }\end{array}$ & 0 & 34 & 59 & 35 & 30 & 18 & 9 & 19 & 13 & 4 \\
\hline $\begin{array}{c}\text { Low-carbon } \\
\text { economy }\end{array}$ & 34 & 0 & 18 & 9 & 6 & 11 & 3 & 4 & 5 & 0 \\
\hline $\begin{array}{c}\text { Energy } \\
\text { consumption }\end{array}$ & 59 & 18 & 0 & 10 & 13 & 6 & 0 & 5 & 5 & 1 \\
\hline $\begin{array}{l}\text { LMDI } \\
\text { model }\end{array}$ & 35 & 9 & 10 & 0 & 7 & 1 & 3 & 2 & 0 & 0 \\
\hline $\begin{array}{l}\text { Economy } \\
\text { growth }\end{array}$ & 30 & 6 & 13 & 7 & 0 & 2 & 1 & 1 & 1 & 0 \\
\hline $\begin{array}{l}\text { Climate } \\
\text { change }\end{array}$ & 18 & 11 & 6 & 1 & 2 & 0 & 5 & 0 & 1 & 1 \\
\hline $\begin{array}{l}\text { Carbon } \\
\text { reduction }\end{array}$ & 9 & 3 & 0 & 3 & 1 & 5 & 0 & 0 & 0 & 0 \\
\hline $\begin{array}{l}\text { Decomposi- } \\
\text { tion analysis }\end{array}$ & 19 & 4 & 5 & 2 & 1 & 0 & 0 & 0 & 2 & 0 \\
\hline $\begin{array}{l}\text { Industrial } \\
\text { structure }\end{array}$ & 13 & 5 & 5 & 0 & 1 & 1 & 0 & 2 & 0 & 2 \\
\hline Low-carbon & 4 & 0 & 1 & 0 & 0 & 1 & 0 & 0 & 2 & 0 \\
\hline
\end{tabular}

\section{$3 \mathrm{CO}_{2}$ emissions: status and trends}

\subsection{Increasingly carbon emissions and its driving force}

At the present, because of the economic development, rapid urbanization and the energy-consuming activities undertaken in the society, a short-term reduction in China's carbon emissions is impossible.

Since 2000, carbon emissions of global fossil fuels burning grow by $3 \%$ annually, with two-thirds coming from China (Gu et al., 2009). China's carbon emissions continue to increase, surpassing the United States as the largest emitter in 2006 and accounting for $20 \%$ of global emissions. Between 2006 and 2013, emissions rise by an average of 15.7\% annually from 4.97 to 10.44 billion tons, which is $29 \%$ of the world's total (Yue et al., 2010).

The main sources of carbon emissions are industrial, agricultural, and household; however, the industrial fossil fuels consumption is the primary contributor. Carbon emissions in eastern China are apparently higher than the less developed central and western regions. Moreover, there are significant regional differences in carbon emissions of the industry, construction, and transportation (Sun et al., 2010).

Great deals of studies use decomposition and econometric models to explore the driving forces of carbon emissions; the most widely used models are structural decomposition analysis (SDA), indexed decomposition analysis (IDA) and production-theory decomposi- 
tion analysis (PDA) (Zhang and Da, 2015). For analyzing energy consumption or carbon emissions, SDA is often combined with the input-output model, and the Logarithmic Mean Divisia Index (LMDI) is most prominently used in the IDA (Cansino et al., 2015). Of all the decomposition factors (Table 3), economic development and increased energy consumption are the greatest drivers of carbon emissions, but with the advance of technology, the improvement of energy efficiency will become the most important factor in carbon emissions reductions. The STIRPAT (Stochastic Impacts by Regression on Population, Affluence, and Technology) model used by Qu Shenning (2010) projects that China's carbon emissions will peak either in 2035 or during 2020-2035, with the amount falling between 2.4-3.3 PgC/a (Hu et al., 2008; Qu et al., 2010; Yue et al., 2010).

Table 3 Studies of contributors to the changes of $\mathrm{CO}_{2}$ emissions in China

\begin{tabular}{|c|c|c|c|c|c|c|}
\hline \multirow{2}{*}{ Authors } & \multirow{2}{*}{ Methods } & \multirow{2}{*}{ Time } & \multirow{2}{*}{$\begin{array}{l}\text { Research } \\
\text { subjects }\end{array}$} & \multicolumn{3}{|c|}{ Decomposition of impact factors } \\
\hline & & & & Impact factors & $\begin{array}{l}\text { Promoting } \\
\text { factors }\end{array}$ & $\begin{array}{l}\text { Inhibitory } \\
\text { factors }\end{array}$ \\
\hline $\begin{array}{l}\text { Zhu and } \\
\text { Zhang, } \\
2011\end{array}$ & IDA & 1995-2008 & $\begin{array}{l}\text { Carbon } \\
\text { emission } \\
\text { intensity }\end{array}$ & $\begin{array}{l}\text { Energy intensity, energy } \\
\text { structure, industrial structure }\end{array}$ & $\begin{array}{l}\text { Energy inten- } \\
\text { sity }\end{array}$ & $\begin{array}{l}\text { Energy struc- } \\
\text { ture, industrial } \\
\text { structure }\end{array}$ \\
\hline $\begin{array}{l}\text { Zhao et } \\
\text { al., } 2014\end{array}$ & $\begin{array}{l}\text { Spatial } \\
\text { Panel } \\
\text { Data } \\
\text { Analysis }\end{array}$ & 1991-2010 & $\begin{array}{l}\text { Carbon emis- } \\
\text { sion intensity } \\
\text { of energy } \\
\text { consumption }\end{array}$ & $\begin{array}{l}\text { Per capita GDP, population } \\
\text { density, energy consumption } \\
\text { structure, transportation, en- } \\
\text { ergy price }\end{array}$ & $\begin{array}{l}\text { Per capita } \\
\text { GDP, popula- } \\
\text { tion density }\end{array}$ & $\begin{array}{l}\text { Energy } \\
\text { consumption } \\
\text { structure }\end{array}$ \\
\hline $\begin{array}{l}\text { Liu and } \\
\text { Liu, } \\
2009\end{array}$ & LMDI & $1992-2005$ & $\begin{array}{l}\text { Carbon } \\
\text { emissions of } \\
\text { industrial } \\
\text { combustion }\end{array}$ & $\begin{array}{l}\text { Energy consumption, energy } \\
\text { structure, technical factors, } \\
\text { intermediate inputs, industrial } \\
\text { structure, industrial output }\end{array}$ & $\begin{array}{l}\text { Energy } \\
\text { consumption, } \\
\text { energy struc- } \\
\text { ture, industrial } \\
\text { output }\end{array}$ & \\
\hline $\begin{array}{l}\text { Song } \\
\text { and Lu, } \\
2009\end{array}$ & LMDI & 1990-2005 & $\begin{array}{l}\text { Carbon } \\
\text { emissions of } \\
\text { energy } \\
\text { consumption }\end{array}$ & $\begin{array}{l}\text { Output scale, energy struc- } \\
\text { ture, emission intensity, en- } \\
\text { ergy intensity }\end{array}$ & Output scale & $\begin{array}{l}\text { Energy } \\
\text { intensity }\end{array}$ \\
\hline $\begin{array}{l}\text { Li et al., } \\
2011\end{array}$ & Kaya & 1993-2008 & $\begin{array}{l}\text { Agricultural } \\
\text { carbon } \\
\text { emission }\end{array}$ & $\begin{array}{l}\text { Economic development, effi- } \\
\text { ciency factor, structure factor, } \\
\text { labor force scale }\end{array}$ & $\begin{array}{l}\text { Economic } \\
\text { development }\end{array}$ & $\begin{array}{l}\text { Efficiency } \\
\text { factor, structure } \\
\text { factor, labor } \\
\text { force scale }\end{array}$ \\
\hline $\begin{array}{l}\text { Yang } \\
\text { and Liu, } \\
2012\end{array}$ & $\begin{array}{l}\text { STIRPA } \\
\mathrm{T}, \mathrm{EKC}\end{array}$ & 1995-2009 & $\begin{array}{l}\text { Carbon } \\
\text { emissions }\end{array}$ & $\begin{array}{l}\text { Per capita GDP, population } \\
\text { size, energy intensity, energy } \\
\text { structure, industrial structure, } \\
\text { urbanization rate, trade } \\
\text { openness, foreign direct in- } \\
\text { vestment }\end{array}$ & $\begin{array}{l}\text { Per capita } \\
\text { GDP, energy } \\
\text { intensity }\end{array}$ & \\
\hline $\begin{array}{l}\text { Guo, } \\
2010\end{array}$ & LMDI & 1995-2007 & $\begin{array}{l}\text { Carbon } \\
\text { emissions }\end{array}$ & $\begin{array}{l}\text { Economic aggregate, eco- } \\
\text { nomic structure, energy use } \\
\text { efficiency, energy consump- } \\
\text { tion structure, carbon emis- } \\
\text { sion coefficient }\end{array}$ & $\begin{array}{l}\text { Economic } \\
\text { aggregate }\end{array}$ & $\begin{array}{l}\text { Energy use } \\
\text { efficiency }\end{array}$ \\
\hline
\end{tabular}

In addition to the studies assessing China's total carbon emissions, there is also a wealth of researches on the emissions of individual industries, such as the textile (Lin and Moubarak, 2013), steel (Lin and Wang, 2015), and cement industries (Shen et al., 2014). Most studies use a direct measure to estimate carbon emissions, leaving out the amounts generated through transportation and other intermediate processes; however, carbon footprint can help 
to correct this deficiency (Yang and Chen, 2014). Carbon footprint is a comprehensive method, including both direct and indirect emissions to assess the amount of $\mathrm{CO}_{2}$ produced in a region; it can be a useful tool in adjusting the climate legislation to localized development, reflecting the connections between local activity and climate change, and increasing the local understanding of climate change (Ramachandra, 2012).

\subsection{Carbon emissions reductions and climate change}

Governmental organizations around the world actively explore strategies for reducing carbon emissions and coping with the climate change. Energy-saving and emission-reduction have become the "green barrier" to international trade in order to protect the environment (Wang et al., 2015).

In response to climate change, many countries have proposed emission reduction targets, such as the European Union's "Strategic Energy Technology Plan" and the United States' target of $80 \%$ reductions by 2050 compared to 1990 . Responding to international pressure, China pledges to reduce its carbon intensity of per unit GDP by $40 \%-45 \%$ for 2020 comparing with 2005, aiming to reach its emissions peak level by 2030 (Bi, 2015). Since 2014, China's "12th Five-Year Plan" has addressed climate change targets, achieving the positive results by restructuring industries, increasing the efficiency of energy consumption, optimizing energy structures, limiting greenhouse gas emissions of non-energy activities and expanding forest carbon sinks. In 2014, China's $\mathrm{CO}_{2}$ emissions of per unit GDP decreased by $6.2 \%$, completing the $92.3 \%$ of carbon intensity reduction target proposed by the " 12 th Five-Year Plan" (NDRC, 2015).

Carbon trading, an important tool of the Kyoto Protocol agreement, is used to achieve international cooperation to mitigate climate change. Thus, an increasing amount of researches will focus on the carbon emissions trading pilot program and the possible carbon trading market to achieve emission reduction targets through carbon trading (Grubb, 2012). While exploring ways to achieve emission reductions, it is important to note the reconstruction role of international trade in globe carbon emission distribution, and the embodied carton emissions in carbon trading should be the focuses of the future researches (Zhang et al., 2015).

\section{Energy consumption trends and the linkage between energy consump- tion and carbon emission}

\subsection{Energy consumption and its economic impact factors}

China's energy consumption is not only massive but increasing as well. Moreover, the regional differences are very large in energy consumption, which are affected by many factors with economic factors being the most obvious.

Energy is crucial significant for human existence and social development. Along with China's economic growth, energy consumption has risen accordingly (Figure 2); in the past 10 years, this trend has been changing rapidly, which is 4.26 billion TCE in 2014, up by $13.65 \%$ from the previous year. For the energy consumption, coal, as the major consumption, has fallen from $90 \%$ of total China's energy consumption in the 1950 s to only $66 \%$ in 2014 ; while oil consumption has been generally steady for the past 30 years. 


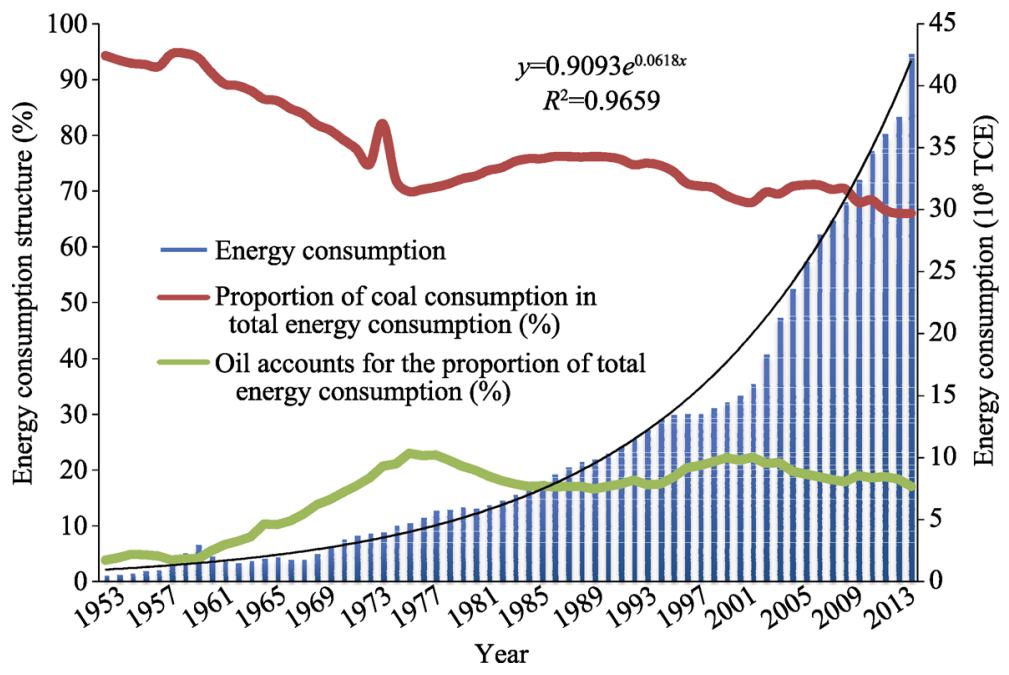

Figure 2 The trend of energy consumption from 1953 to 2013 in China

In China, spatial-temporal distribution differences of energy consumption are relatively large, decreasing geographically from east to west, though per capita consumption is clearly higher in the west. Energy consumption is still concentrated along China's east coastal area at least until the mid-21st century, while energy supply remains located in the "three-northern" regions, namely east, central and west (Liu and Shen, 2011).

Decomposition models are also most used to study the impact factors of energy consumption, such as LMDI. The main factors are concentrated on three aspects of the scale, technology and structure, including economic growth, population size, urbanization, industrial structure and natural endowments. Among these, economic growth is the most impactful factor (Yang et al., 2013). Many studies have shown that country's economic fluctuations will influence the energy consumption changes. Furthermore, when China's GDP growth is below $18.04 \%$, a steady linear relationship can be got between GDP and energy consumption; however, when growth exceeds $18.04 \%$, the relationship becomes nonlinear, with a $1 \%$ rise in GDP and a $2.26 \%$ rise in energy consumption. This illustrates the crucial role of economic growth in accelerating the energy consumption (Du et al., 2009; Zhao and Fan, 2007). This paper establishes a simple comparison of China's GDP and energy consumption during 1953-2014 in order to illustrate the related research findings. At the same time, it reveals that energy intensity has consistently decreased. GDP growth promotes the energy demands and energy consumption, as well as the improvement of energy efficiency. In the future, more new energy should be exploited and energy efficiency should be further improved. Moreover, the industrial structure should be adjusted to reduce the energy dependency (Zhao and Fan, 2011).

\subsection{Continued increase in energy demand}

China's energy demands are constantly increasing and energy security must be strengthened to support the balance between energy supply and demand.

According to the International Energy Agency's (IEA) predictions (IEA, 2010), China's energy demand in 2035 will be twice the level in 2008 , comprising about $23.4 \%$ of the 
world's total, up from $17.4 \%$ in 2008 (Table 4). Considering the current energy consumption structure, the future development will remain dependent on domestic sources of energy, with coal consumption remaining the leading supply, and oil imports will uninterruptedly increase (Zhang, 2013).

Table 4 The forecast for energy demand in China

\begin{tabular}{|c|c|c|c|c|c|c|c|}
\hline & \multicolumn{5}{|c|}{ Energy demand (100 million tons of standard coal) } & \multicolumn{2}{|c|}{ Proportion $(\%)$} \\
\hline & 1990 & 2008 & 2020 & 2030 & 2035 & 2008 & 2035 \\
\hline Coal & 7.78 & 20.55 & 30.60 & 35.22 & 37.43 & 66 & 61 \\
\hline Petroleum & 1.66 & 5.37 & 8.25 & 10.15 & 10.98 & 17 & 18 \\
\hline Natural gas & 0.19 & 1.03 & 2.60 & 3.93 & 4.74 & 3 & 8 \\
\hline New energy & 0.00 & 0.26 & 1.80 & 2.53 & 2.75 & 1 & 4 \\
\hline Hydrogen & 0.16 & 0.73 & 1.34 & 1.54 & 1.63 & 2 & 3 \\
\hline Biomass energy & 2.91 & 2.95 & 2.78 & 2.68 & 2.85 & 10 & 5 \\
\hline Renewable energy & 0.00 & 0.10 & 0.47 & 0.79 & 0.92 & 0 & 1 \\
\hline Total & 12.68 & 30.99 & 47.82 & 56.82 & 61.30 & 100 & 100 \\
\hline
\end{tabular}

Shen Lei et al. (2015) suggest that China will be in the stage of low energy consumption growth after 2035, with the amount reaching 6.19-12.13 billion TCE in 2050. Although energy demands seem to be endlessly on the rise, the rate of increase is actually decreasing; so there is a hope that one day there will be an energy consumption plateau, and perhaps a decoupling of economic growth and energy consumption.

In order to keep a balance between supply and demand, it is crucial to ensure the energy security, including supply, production, utilization, transportation and environmental safety. It is important to establish a comprehensive energy management system to improve the energy efficiency and provide the diversification of energy sources. We should develop the new techniques, alternative energy and transportation capacity to safeguard the national energy security and satisfy the increasing energy consumption demands (Shen and Xue, 2011).

\subsection{Energy consumption effect: increasing carbon emissions}

In the literature collected for this study, of the 400 articles under the theme "energy consumption", nearly $20 \%$ are related to the carbon emissions. And it has been a popular research topic since 2002, and carbon emission is the main result of energy consumption (Liu et al., 2002).

Globally, the burning of fossil fuels contributes to $70 \%$ of total carbon emissions. China is currently in a period of rapid economic growth, and its present coal-based energy structure is difficult to change. Currently, $80 \%$ of China's energy demands are met by fossil fuels, so emissions caused by energy consumption may be the main part of the atmospheric carbon emission. Special attention should be given to the studies about the energy consumption and carbon emissions to explore the low-carbon pathways (Cui, 2015; Zhang et al., 2012).

Comparing the changing trend of China's energy consumption and carbon emissions (Figure 3), we discover that the two exhibit the same trends, indicating the strong positive correlation between them. Research by Wu Hong et al. (2011) has proved the existence of a positive correlation between energy consumption and carbon emissions, as well as energy 
intensity and carbon emission intensity; there exits the direct Granger causality. Thus, with every $1 \%$ rise in energy consumption, carbon emissions rise by $1.16 \%$. The effects of energy consumption on carbon emissions are clear and energy consumption is the most important cause of China's $\mathrm{CO}_{2}$ emissions ( $\mathrm{Liu}$, 2011).

In 2011, the burning of fossil fuels produces 7.99 billion tons of $\mathrm{CO}_{2}, 25.4 \%$ of the world's total emissions. In 2015, this figure increases to 8.01 billion tons; and with the continued rise in national

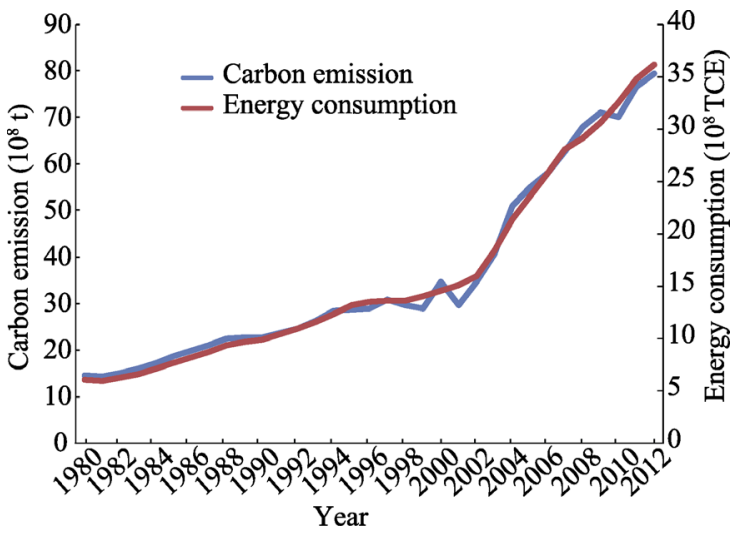

Figure 3 The linkage between energy consumption and carbon emission from 1980-2012 in China energy demand, $\mathrm{CO}_{2}$ emissions are expected to continue to grow at a fast rate (IEA, 2013).

\section{Low-carbon economic models for mitigating climate change}

\subsection{The connection between economic growth, energy consumption and carbon emis- sions}

China's economy is overly dependent on energy consumption, which is the primary source of greenhouse gases. However, it is becoming evident that energy, which is a scarce natural resource, is restraining economic growth. Thus, it is clear that the interconnectedness of energy consumption, carbon emissions and economic development deserves our more attention (Wu et al., 2013).

For the developed countries, the relation between economic growth and greenhouse gas emissions has been partially decoupled, while developing countries show a significant correlation (Contestabile, 2012). Researches about the nexus between energy consumption, carbon emissions and economic growth are concentrated on exploring the environmental Kuznets curve (EKC). Grossman, who believes that per capita income and environmental pollution exhibit an inverted "U-shaped" relationship, first proposes this curve (Grossman and Krueger, 1991). Panayotou (1997) subsequently sought to prove this concept, proposing the name "environmental Kuznets curve" firstly. There are dynamic relations between economic growth, energy consumption and the environment, where energy consumption may have an immediate positive effect on economic growth; however, this will do damage to environment (Kolstad and Krautkraemer, 1993). Subsequent studies have also discovered an inverted "U-shaped" link between per capita income and carbon emissions (Holtz-Eakin and Selden, 1995). Although Chinese scholars' related researches begin relatively late, they make good use of statistical data, conduct quantitative analyses and find the similar results (He and Liu, 2004; Kuang, 2009). Zhao and Li (2011) pointed out that for every $1 \%$ increase in China's GDP, carbon emissions rise by $0.36 \%$. And carbon emissions and economic growth present an inverted "U-shaped" relationship, with the underlying mechanism of economic growth leading to energy consumption, which leads to larger carbon emissions (Chen and Zhang, 2012; Wang, 2014; Zhang and Cheng, 2009). Inversely, changes of carbon 
emissions also influence the economic growth and energy consumption, so there is the causation relationship between them (Figure 4).

At present, the rapid economic development of China depends on increasing energy consumption largely, resulting in carbon emissions. In order to achieve the carbon emission reductions target, we should improve the structure of economic development and energy consumption, increase the energy consumption efficiency, and promote the technological innovation. In the future, low-carbon economy will be the major model of economic development.

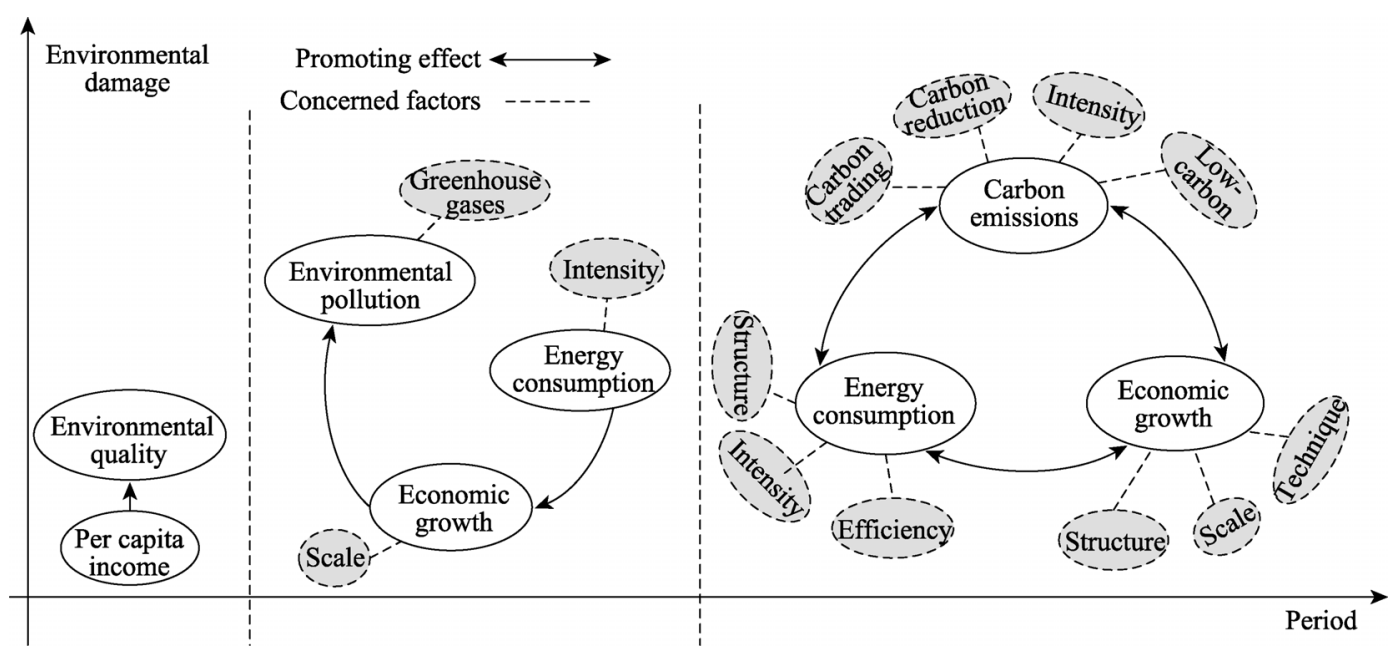

Figure 4 The tendency of linkage between carbon emission, energy consumption and economic development

\subsection{Development of low-carbon economy}

Low-carbon economy has appeared initially in the UK government white paper entitled "Our Future: Creating a Low-Carbon Economy" in 2003, and it is a low-carbon development model of low consumption, low pollution, and low emissions. The white paper presents a new combination of energy innovation, emissions reduction technology, industrial structure innovation and human society development. It is an ideal economic model for reducing greenhouse gas emissions, realizing reductions targets, confronting global warming, and decoupling the connection between economic growth, energy consumption and carbon emissions (Song, 2010; Fu et al., 2008; Liu et al., 2010).

Since the establishment of low-carbon economy, Chinese scholars have begun to develop more applications than the theories (Figure 5). Currently, China's low-carbon economic

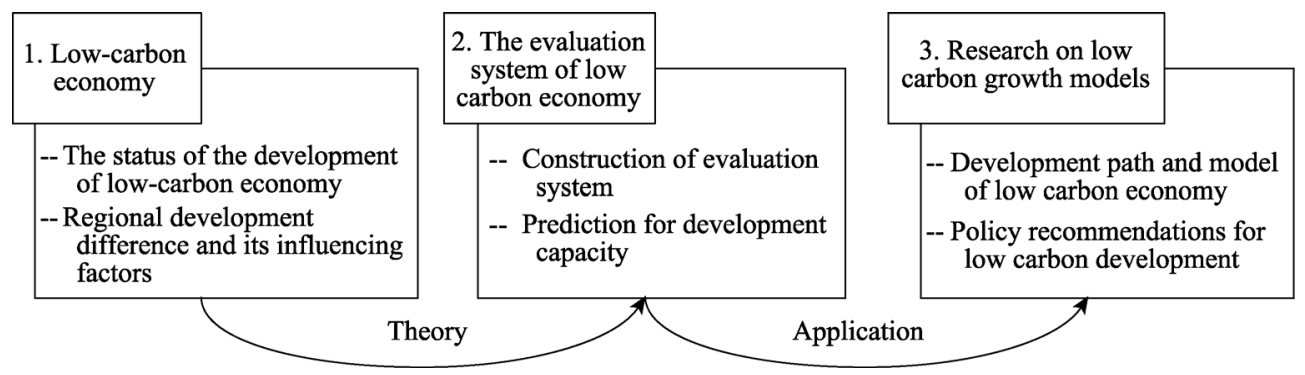

Figure 5 Transition from theory to application about study on low-carbon economy 
development exhibits a great difference between regions. The patterns of low-carbon economy in the eastern provinces are gradually formed. However, comparing to the eastern provinces, the western provinces' low-carbon economic development is more influenced by energy structures, populations, economic development and consumption types. Generally speaking, we should embark from the local actual situation to develop low carbon economy, carefully designing the institutional arrangements to meet different development levels of different regions in our country (Li et al., 2015).

\subsection{Methods for establishing a low-carbon economy and policy recommendations}

The goal of the low-carbon economy is to reduce carbon emissions, by lowering the energy consumption.

For structure adjustment, it is essential to reform the energy and industrial structure to achieve a low-carbon economy. In transforming the Chinese energy structure from one based on coal to a low-carbon one, China should follow the strategy of replacing fossil fuels with new and clean energy. In 2014, China's GDP of tertiary industries are 9.2\%, 42.6\%, and $48.2 \%$, and it is an improvement from 2013 (NDRC, 2015). In future, it will be important to further eliminate the high consumption and heavy polluting industries of the secondary economic sector, achieving a reasonable low-carbon energy structure. In China, developing the low-carbon industry and the circular economy is significant to realize the low-carbon economy. Structure adjustment will contribute $62 \%-67 \%$ of the emission reduction targets (Lin and Liu, 2011; Zhang and Duan, 2012).

From the viewpoint of technology, it is vital to improve energy efficiency and promote the widespread use of low-carbon technologies. In 2014, China's energy consumption of per unit GDP falls by $4.8 \%$, saving about 600 million TCE and 140 million tons of $\mathrm{CO}_{2}$ emissions. In the same year, $\mathrm{CO}_{2}$ emissions of per unit GDP decrease by $5.8 \%$, down by a cumulative $15.8 \%$ from 2010 (NDRC, 2015). At the same time, there are already a great variety of low-carbon technologies in use all over the world, such as the EU's Carbon Capture and Storage (CCS), and the United States' "Climate Change Technology Program", which aims to develop applications of hydrogen fuel cell technology, as well as containing plans for the future of American power and nuclear fusion (Liu et al., 2009).

From a policy perspective, energy consumption reduction could be achieved through regulatory means, taxation and the establishment of an emission-trading scheme. Specific methods should be adopted to reduce the energy consumption, including setting emissions caps, energy consumption or emissions standards, electricity supply quotas and energy or environmental taxes, as well as grants and subsidies (Cao and Zhang, 2010).

Overall, establishing a low-carbon economy will require the comprehensive support of policy, technology and funding. China should select a gentle way, mobilizing the enterprises and public to actively work together, to develop the circular economy pilot projects and build a unified low-carbon economic development system.

\section{Application of methods in the previous studies}

In the research progress on carbon emissions, energy consumption and low-carbon economy in China, many kinds of methods and models are adopted (Table 5). In addition to those listed in Table 5, other methods are also used. For example, a computable general equilib- 
rium (CGE) model for calculating energy consumption and emissions under different economic growth scenarios; the decoupling theory for exploring the relationship between economic growth and environment; a life-cycle assessment for calculating carbon emissions, and the VAR model.

Table 5 The main research methods and models

\begin{tabular}{|c|c|c|}
\hline Method and model & Basic algorithm & Application description \\
\hline $\begin{array}{l}\text { IPCC greenhouse } \\
\text { gas emission inven- } \\
\text { tory preparation } \\
\text { method (Cheng }\end{array}$ & $c=a \times f$ & $\begin{array}{l}C \text { indicates carbon emission, } a \text { is the activity level, } f \text { is the } \\
\text { emission factor. It provides a unified algorithm and refer- } \\
\text { ence standard for the estimation of carbon emission. }\end{array}$ \\
\hline
\end{tabular}

2014)

LMDI model

IPAT model

STIRPAT model

(Song, 2012)

Econometric model

Granger causality tests (Wu et al., 2013)

EKC model

Kaya identical equation

$\ln I=a_{0}+a_{1} \ln A+a_{2}(\ln A)^{2}+$ $a_{3}(\ln A)^{3}+a_{4} \ln P+a_{5} \ln T+\ldots$

$y_{i t}=\alpha_{i}+\beta_{1 i} x_{1 i, t}+\beta_{2 i} x_{1 i, t}$

$+\ldots \beta_{M i} x_{m i, t}+e_{i t}$

If $X$ helps to predict $Y$, then $X$ is the granger cause of $Y$

The relationship between economic development and environmental factors in inverted U-shaped curve

$G H G=\frac{G H G}{T O E} \times \frac{T O E}{G D P} \times \frac{G D P}{P O P} \times P O l$

$=f \times e \times g \times p$

Hierarchical Analysis

Input-output Analysis (Wang et al.,

2015)

Target-Criterion-Scheme
$C=P \times(Y / P) \times(E / Y) \times(C / E)$

$I=P \times A \times T$

$C$ indicates carbon emission, $P$ is the population, $Y / P$ is per capita GDP, $E / Y$ represents the energy consumption intensity, $C / E$ is the energy structure intensity; the method is widely used in carbon emissions calculation and its effect decomposition.

$I$ depicts the impact of evaluation, $P$ is the population, $A$ expresses the wealthy degree, $T$ represents the scientific and technological progress; the model is originally used for environmental impact assessment, after being improved for carbon dioxide impact factor analysis.

The model is an extension of IPAT model, and a new factor is introduced in the model.

$y$ indicates carbon emission, $x$ is the influencing factor of carbon emissions, $\alpha$ is the intercept, $\beta$ is the coefficient, $i$ is the number of cross section, $t$ is the time, $M$ represents the number of influencing factors of carbon emission; compared to the traditional time-series and cross-sectional data model, this model expands the amount of information, with dynamic reliability analysis, which is helpful to reflect the system structure.

This model can only be used for the test of smooth sequence, and the information contained in the past $X$ can improve the forecast of $Y$.

Environmental Kuznets curve is used to illustrate the relationship between economic growth and carbon emissions, energy consumption.

$G H G$ indicates the greenhouse gas emissions, TOE represents the energy consumption, GDP is the gross domestic product, $P O P$ is the population, $f$ is the energy structure intensity, $e$ is the energy consumption intensity, $g$ is the per capita $G D P, p$ is the population; the model is mainly used for analysis of the driving factors of carbon dioxide emissions.

The model is a kind of weight decision analysis method, which is mainly used to construct the evaluation system of low carbon economy. It is the basic step for the qualitative and quantitative analysis.

$c$ denotes the energy carbon emissions vector, $f$ is the direct carbon emission vector of the department, $I$ is the intensity matrix, $A$ is the input coefficient matrix, $Y$ is the final demand matrix, $(I-A)^{-1}$ is the Leontief inverse matrix; this model is used to analyze the carbon emissions of intermediate products in the economic operation process. 


\section{Conclusions}

After literature comprehensive comparison and analysis, we found that most current studies concerning energy consumption, carbon emissions and low-carbon economies primarily have the following clear features.

First, the study of carbon emissions, energy consumption and low-carbon economies in China is developing rapidly, and presents many interesting results. Research contents involve the structural analysis, distribution pattern analysis, influencing factors and policy recommendations. The research fields involve geography, climatology, ecology and environmental economics. The scope of research, which is expanding daily, has spread from the national to industrial levels and from one-dimensional to multi-dimensional.

Second, bulks of studies show that there exists an inverted "U-shaped" linkage between economic development, energy consumption and carbon emission. Energy consumption in China will be in a low-speed growth after 2035 and it is expected to peak between 6.1912.13 billion TCE in 2050. China's carbon emissions are expected to peak in 2035, or between 2020-2045, and the optimal range of carbon emissions is between 2.4-3.3 PgC/year. Recently, the connection between them also follows the rule of "economic development $\rightarrow$ energy consumption $\rightarrow$ carbon emissions". For this reason, in order to safeguard the economic growth, we must find ways to reduce carbon emissions through innovative energy technologies.

Third but not the last, considering the international environment, future research should focus on the following three points. One is about international carbon trading, virtual carbon flows and energy structural reform, which should be paid more attention. Another is about research on the low-carbon economy that is relatively less concerned but a unified theoretical basis should be formed. As a result, the future research should focus on the improvement of theories towards green, circular, low-carbon economies and models. Studies of the low-carbon economy could be scaled down, focusing on micro-level analyses of low-carbon communities, households and personal behaviors. The last issue is about comprehensive evaluation methodology of carbon emissions, energy consumption and economic growth which should be established. Although the above three research areas have their own methods and theoretical bases, they all need a unified spatial analysis method. To end this objective, we strongly suggest that is necessary to establish a unified system for correctly evaluating the potential and sophisticated nexus among the carbon emissions, energy consumptions and low-carbon economy in further studies either in China or the world.

\section{References}

Andres R J, Marland G, Fung I et al., 1996. A 1 degrees x1 degrees distribution of carbon dioxide emissions from fossil fuel consumption and cement manufacture, 1950-1990. Global Biogeochemical Cycles, 10(3): 419-429.

Begum R A, Sohag K, Abdullah S M S et al., 2015. $\mathrm{CO}_{2}$ emissions, energy consumption, economic and population growth in Malaysia. Renewable and Sustainable Energy Reviews, 41: 594-601.

$\mathrm{Bi}$ Chao, 2015. Scheme and policies for peaking energy carbon emission in China. China Population Resources and Environment, 25(5): 20-27. (in Chinese)

Cansino J M, Sánchez-Braza A, Rodríguez-Arévalo M L, 2015. Driving forces of Spain's $\mathrm{CO}_{2}$ emissions: A LMDI decomposition approach. Renewable and Sustainable Energy Reviews, 48: 749-759. 
Cao Haixia, Zhang Fuming, 2010. Review of low carbon economy in China and abroad. Productivity Research, (3): 1-6. (in Chinese)

Chen Dehu, Zhang Jin, 2012. An empirical study of the environment Kuznets curve for China's carbon emission: Based on spatial panel model. Statistics \& Information Forum, 27(5): 48-53.

Cheng Hao, 2014. How to calculate the carbon emissions: IPCC national greenhouse gas inventory guide in 2006. China Statistics, (11): 28-30. (in Chinese)

Contestabile M, 2012. Sociology: Economic and emissions trends. Nature Climate Change, 2(10): 709-709.

Cui Jia, 2015. Study of driving factors and spatial driving types of carbon emission intensity in China [D]. Changchun: Jilin University. (in Chinese)

Du Jianli, Lin Zhenshan, Zhang Zhenzhen et al., 2009. Analysis on correlation of the increase of GDP and energy consumption in China based on empirical mode decomposition method. Progress in Geography, 28(1): 119-124. (in Chinese)

Fan J, Wang Q, Sun W, 2015. The failure of China's Energy Development Strategy 2050 and its impact on carbon emissions. Renewable \& Sustainable Energy Reviews, 49: 1160-1170.

Fu Xun, Ma Yonghuan, Liu Yijun et al., 2008. Development patterns of low carbon economy. China Population, Resources and Environment, 18(3): 14-19. (in Chinese)

Greening L A, Greene D L, Difiglio C, 2000. Energy efficiency and consumption: The rebound effect: A survey. Energy Policy, 28(6): 389-401.

Grossman G M, Krueger A B, 1991. Environmental impacts of a North American free trade agreement. National Bureau of Economic Research.

Grubb M, 2012. Emissions trading: Cap and trade finds new energy. Nature, 491(7426): 666-667.

Gu Chaolin, Tan Zongbo, Liu Wan et al., 2009. A study climate carbon emissions and low-carbon city planning. Urban Planning Forum, (3): 38-45. (in Chinese)

Guo Chaoxian, 2010. Decomposition of China's carbon emissions based LMDI. China Population, Resources and Environment, 20(12): 4-9. (in Chinese)

He Jiankun, Liu Bin, 2004. Analysis of carbon emission intensity as the main index for greenhouse gas emission mitigation commitments. Journal of Tsinghua University (Science and Technology), 44(6): 740-743. (in Chinese)

Holtz-Eakin D, Selden T M, 1995. Stoking the fires? $\mathrm{CO}_{2}$ emissions and economic growth. Journal of Public Economics, 57(1): 85-101.

Hu Chuzhi, Huang Xianjin, Zhong Taiyang et al., 2008. Character of carbon emission in China and its dynamic development analysis. China Population, Resources and Environment, 18(3): 38-42. (in Chinese)

International Energy Agency, 2010. World Energy Outlook 2010. Paris: IEA.

International Energy Agency, 2013. $\mathrm{CO}_{2}$ emissions from fuel combustion highlights. Paris: IEA.

Kolstad C D, Krautkraemer J A, 1993. Natural resource use and the environment. Handbook of Natural Resource and Energy Economics, (3): 1219-1265.

Kuang Xinrui, 2009. A research on China's economic development and $\mathrm{CO}_{2}$ emission [D]. Wuxi: Jiangnan University. (in Chinese)

Li Bo, Zhang Junbiao, Li Haipeng, 2011. Research on spatial-temporal characteristics and affecting factors decomposition of agricultural carbon emission in China. China Population, Resources and Environment, 21(8): 80-86. (in Chinese)

Li Xin, Wang Haibin, Chen Chaozhen et al., 2015. Inter-provincial discrepancy and spatiotemporal characteristics of carbon dioxide emission intensity from power energy consumption in China. Journal of Arid Land Resources and Environment, 29(1): 43-47. (in Chinese)

Lin B Q, Moubarak M, 2013. Decomposition analysis: change of carbon dioxide emissions in the Chinese textile industry. Renewable \& Sustainable Energy Reviews, 26: 389-396.

Lin B Q, Wang X L, 2015. Carbon emissions from energy intensive industry in China: Evidence from the iron \& steel industry. Renewable \& Sustainable Energy Reviews, 47: 746-754.

Lin Jinhui, Liu Jun, 2011. Antidumping jumping FDI employment and welfare of the host country. On Economic 
Problems, (3): 37-40, 56. (in Chinese)

Liu Hongguang, Liu Weidong, 2009. Decomposition of energy-induced $\mathrm{CO}_{2}$ emissions in industry of China. Progress in Geography, 28(2): 285-292.

Liu Hui, Cheng Shengkui, Zhang Lei, 2002. The international latest research of the impacts of human activities on carbon emission. Progress in Geography, 21(5): 420-429.

Liu Lancui, Gan Lin, Cao Dong et al., 2009. Analysis and enlightenment from climate policies of major economies. Sino-Global Energy, 14(9): 1-8. (in Chinese)

Liu Litao, Shen Lei, 2011. Scenario analysis of energy zoning and function orientation on sustainable development of China. Journal of Natural Resources, 26(9): 1484-1495. (in Chinese)

Liu Weidong, Zhang Lei, Wang Limao et al., 2010. A sketch map of low-carbon economic development in China. Geographical Research, 29(5): 778-788.

Liu Zhixiong, 2011. The relationship between energy consumption, economic growth and carbon emissions in China. Coal Economic Research, (4): 37-41, 65. (in Chinese)

Makarov A A, Bashmakov I, 1991. An energy development strategy for the USSR: Minimizing greenhouse gas emissions. Energy Policy, 19(10): 987-994.

National Development and Reform Commission (NDRC), 2015. The 2015 Annual Report of China's Response to Climate Change Policies and Action. Beijing.

Nulíček V, 1993. Possibilities of reduction of carbon dioxide emissions from energy processes in the Czech Republic. Energy Conversion and Management, 34(9): 753-774.

Ozturk I, Acaravci A, 2010. $\mathrm{CO}_{2}$ emissions, energy consumption and economic growth in Turkey. Renewable and Sustainable Energy Reviews, 14(9): 3220-3225.

Panayotou T, 1997. Demystifying the environmental Kuznets curve turning a black box into a policy tool. Environment and Development Economics, 2(4): 465-484.

Qin Dahe, 2014. Climate change science and sustainable development. Progress in Geography, 33(7): 874-883. (in Chinese)

Qu Shenning, Guo Chaoxian, 2010. Forecast of China's carbon emission based on STIRPAT model. China Population, Resources and Environment, 20(12): 10-15. (in Chinese)

Ramachandra T V, 2012. Decentralized carbon footprint analysis for opting climate change mitigation strategies in India. Renewable \& Sustainable Energy Reviews, 16(8): 5820-5833.

Shen L, Gao T M, Zhao J A et al., 2014. Factory-level measurements on $\mathrm{CO}_{2}$ emission factors of cement production in China. Renewable \& Sustainable Energy Reviews, 34: 337-349.

Shen Lei, Liu Litao, Wang Limao et al., 2015. 2050 energy consumption projection for China. Journal of Natural Resources, 30(3): 361-373. (in Chinese)

Shen Lei, Xue Jingjing, 2011. Development path choice and strategy framework of China's energy security. China Population, Resources and Environment, 21(10): 49-54. (in Chinese)

Song Deyong, Lu Zhongbao, 2009. The factor decomposition and periodic fluctuations of carbon emission in China. China Population, Resources and Environment, 19(3): 18-24. (in Chinese)

Song Dongfeng, 2010. Current situation of China's low-carbon economy. Ecological Economy, (9): 85-87. (in Chinese)

Song Xiaohui, Zhang Yufen, Wang Yimei et al., 2012. Analysis of impacts of demographic factors on carbon emission based on the IPAT model. Research of Environmental Sciences, 25(1): 109-115. (in Chinese)

Sun Jianwei, Zhao Rongxin, Huang Xianjin et al., 2010. Research on carbon emission estimation and factor decomposition of China from 1995-2005. Journal of Natural Resources, 25(8): 1284-1295. (in Chinese)

Tunç G I, Türüt-Aşı S, Akbostancı E, 2009. A decomposition analysis of $\mathrm{CO}_{2}$ emissions from energy use: Turkish case. Energy Policy, 37(11): 4689-4699.

Wang Qian, 2014. Research on the affecting factors of carbon emissions in Guangdong based on LMDI [D]. Guangzhou: Guangdong Academy of Social Sciences. (in Chinese)

Wang Saojian, Liu Yanyan, Fang Chuanglin, 2015. Review of energy-related $\mathrm{CO}_{2}$ emission in response to climate change. Progress in Geography, 34(2): 151-164. (in Chinese) 
Wang Yuan, Zhao Lixia, Yu Xia et al., 2015. Carbon emission change of energy consumption and its stress evaluation on local climate change in Shanghai. Journal of Fudan University (Natural Science), (4): 439-448. (in Chinese)

Wu Hong, Gu Shuzhong, Guang Xingliang et al., 2013. Analysis on relationship between carbon emission from fossil energy consumption and economic growth in China. Journal of Natural Resources, 28(3): 381-390. (in Chinese)

Wu Hong, Gu Shuzhong, Zhou Hong et al., 2011. Relationship between energy consumption, carbon emissions and economic growth in Hebei province. Resources Science, 33(10): 1897-1905. (in Chinese)

Yan Qiongwei, Chen Hao, 2011. Research on the relationship between GDP and energy consumption. China Population, Resources and Environment, 21(7): 13-19. (in Chinese)

Yang Jian, Liu Huajun, 2012. Regional difference decomposition and influence factors of China's carbon dioxide emissions. The Journal of Quantitative \& Technical Economics, (5): 36-49, 148. (in Chinese)

Yang Wei, Wang Chengjin, Jin Fengjun et al., 2013. Decomposition of energy intensity change in industrial sub-sectors and its spatial-temporal variation in China. Journal of Natural Resources, 28(1): 81-91. (in Chinese)

Yang J, Chen B, 2014. Carbon footprint estimation of Chinese economic sectors based on a three-tier model. Renewable \& Sustainable Energy Reviews, 29: 499-507.

Yue Chao, Wang Shaopeng, Zhu Jiangling et al., 2010. 2050 carbon emissions projection for China-carbon emission and social development. Acta Scientiarum Naturalium Universitatis Pekinensis, 46(4): 517-524. (in Chinese)

Zhang Li, Lei Jun, Zhang Xiaolei, 2012. Variations and influential factors of carbon emission of primary energy consumption in Xinjiang during the period 1952-2008. Resources Science, 34(1): 42-49. (in Chinese)

Zhang Weiyang, Duan Xuejun, 2012. The research progress in the relationship among economic growth, industrial structure, and carbon emissions. Progress in Geography, 31(4): 442-450. (in Chinese)

Zhang X P, Cheng X M, 2009. Energy consumption, carbon emissions, and economic growth in China. Ecological Economics, 68(10): 2706-2712.

Zhang Xu, Qi Tianyu, Zhang Da et al., 2015. Research focus and trend of energy development and climate change. Renewable Energy Resources, (8): 1214-1218. (in Chinese)

Zhang Y J, Da Y B, 2015. The decomposition of energy-related carbon emission and its decoupling with economic growth in China. Renewable \& Sustainable Energy Reviews, 41: 1255-1266.

Zhang Z X, 2013. An analysis of China's energy demand and supply policy framework. Wiley Interdisciplinary Reviews: Energy and Environment, 2(4): 422-440.

Zhao Aiwen, Li Dong, 2011. Co-integration and causal relationship between carbon emission and economic growth in China. Resources and Environment in the Yangtze Basin, 20(11): 1297-1303.

Zhao Jinwen, Fan Jitao, 2007. Empirical research on the inherent relationship between economy growth and energy consumption in China. Economic Research Journal, 8: 31-42. (in Chinese)

Zhao X T, Burnett J W, Fletcher J J, 2014. Spatial analysis of China province-level $\mathrm{CO}_{2}$ emission intensity. Renewable \& Sustainable Energy Reviews, 33: 1-10.

Zhu Ling, Zhang Zhen, 2011. Decomposition analysis of carbon emission intensity in Shanghai city. Research of Environmental Sciences, 24(1): 20-26. (in Chinese) 